\title{
Design of Computer Control System of Vehicle Engine Cooling System
}

\author{
Qingguo Luo ${ }^{12}$ \\ Department of Mechanical Engineering, Academy of Armored Forces Engineering,Beijing, 100072, \\ China \\ E-mail: Iqg_zgy@163.com
}

\section{Hongtao Yin}

Department of Mechanical Engineering, Academy of Armored Forces Engineering,Beijing, 100072, China

E-mail: yinht20060126.com

\section{Xingxing Ning}

Department of Mechanical Engineering, Academy of Armored Forces Engineering,Beijing, 100072, China

E-mail:jshw81a@163.com

\begin{abstract}
As to the engine coolant temperature control system, a vehicle cooling system simulation model is established, which has been verified by bench test model. Control strategies of PI feedback control and feed forward-feedback control are designed on the basis of this model. These three kinds of cooling system control strategies are compared and analyzed in warm, load mutation and in the New European Driving Cycle (NEDC) by considering the consumption of cooling system. The results show that PI feedback control strategy can make temperature fluctuation at the engine coolant outlet within $\pm 1.5^{\circ} \mathrm{C}$ and $\pm 0.5^{\circ} \mathrm{C}$ of the comprehensive control strategy. PI feedback control strategy and the comprehensive control strategy can reduce the warm-up time and the power consumption by $55.3 \%$ and $58.0 \%$ respectively than the original machine. The coolant temperature fluctuation with the integrated control strategy of feed forward-feedback is smaller than that of PI feedback control strategy; and it can further reduce the power consumption of cooling system.
\end{abstract}

CENet2015

12-13 September 2015

Shanghai, China

\footnotetext{
${ }^{1}$ Speaker

${ }^{2}$ Correspongding Author
} 


\section{Introduction}

With development of the automobile technology, the improved engine power and the engine compartment interior space have become more compacted under stricter emissions regulations. The design of the cooling system of engine cooling system is increasingly demanding. The traditional account of high speed and high load reliability in the design, in accordance with the maximum torque to design and the maximum power condition to check the result, will undoubtedly produce the phenomenon of excess cooling under partial loading condition[1]. In the environment of high temperature and high load conditions, it has the risk of overheating. Studies have shown that the vehicle cooling system only work at the running time of 3\%-5\% in the design ability[2]. The coolant temperatures of traditional cooling system below with the optimum temperature and the cooling system accessories of high energy consuming will have a negative impact on the fuel consumption.

Traditional mechanical cooling system has been replaced by the intelligent cooling system[3-5]. System structure of intelligent cooling system includes a controllable electric water pump, an electric fan and a smart thermostat. Compared with traditional cooling system passive regulating, the intelligent cooling system can control the coolant temperature in the optimum temperature range under all working conditions; thus research on the control strategy of the cooling system is also to be concerned.

In this paper, a passenger car cooling system model is established and the accuracy of the model is verified by application of bench test. This model is based on the design of PI feedback control and feed forward based on the integrated control strategy. The simulation results show that PI feedback control and integrated control can greatly reduce the energy consumption of the cooling system and precise control of the temperature of the coolant while compared to the original engine system. The feed forward and feedback of the integrated control strategy has better control effect as to small coolant fluctuations and low energy consumption.

\section{Modeling of Engine Cooling System}

When modeling, the lumped parameter method is used in consideration of that the parameters distribute uniformly. The heat exchanging among the engine, the cooling pipe and air is ignored. Consider the heat capacity of the engine body and the water tank radiator, which are taken as particles. It is assumed that all the heat the engine combustion chamber transfers to the water jacket of the cylinder block is taken away by cooling system. Take the heat transfer of an engine in the combustion chamber as a function of engine speed and load, which can be determined through the corresponding thermal balance test data according to the following function.

$$
Q_{\text {eng }}=f_{\text {block }}\left(n_{\text {eng }}, D_{\text {eng }}\right)
$$

The working condition of the heat balance data can be estimated by the formula (2.2).

$$
Q_{\text {eng }}=\eta \times M_{\text {fuel }} \times H_{u}
$$

Where: $Q_{\text {eng }}$ is for the combustion chamber heat transfer, $n_{\text {eng }}$ is for the engine speed, $D_{\text {eng }}$ is for the engine load, $\eta$ is for the coefficient of combustion chamber heat transfer and combustion, $M_{\text {fuel }}$ is for the fuel consumption and $H_{u}$ is for the fuel of low calorific value.

The performance of the water tank radiator meets the following equation in respect of heat transfer[6]. 


$$
\frac{\mathrm{d} T_{\text {rad }}}{\mathrm{d} t}=\frac{(h A \Delta \theta)_{c}+(h A \Delta \theta)_{a}}{\rho_{\text {rad }} V_{\text {rad }} C_{\text {rad }}}
$$

Where: $h$ is for the heat transfer coefficient, $A$ is for heat transfer area, $\Delta \theta$ is for the temperature difference between coolant and the wall of radiator surface. $\rho_{\text {rad }}, V_{\text {rad }}$ $C_{\mathrm{rad}}$ is for the heat sink material density, volume and heat capacity respectively, $(h A \Delta \theta)_{c}$ and $(h A \Delta \theta)_{c}$ indicate coolant radiator for heat and radiator of air heat exchange. formula:

The heat transfer coefficient of the radiator can be calculated by the following

$$
N u=C R e_{m} \operatorname{Pr}^{1 / 3}
$$

Where $^{N u=\left(\frac{h L}{k}\right)}, R_{e}=\left(\frac{\rho \mu L}{\mu}\right), P r=\left(\frac{\mu C_{p}}{k}\right), N u$ is for the Nusselt number, $R e_{m}$ is for Reynolds number, $\operatorname{Pr}$ is for Prandtl number, $L$ is for a characteristic length, $\rho$ is for fluid density and $C_{p}$ is for the heat capacity of coolant, $\mu$ is for the viscosity of fluid dynamics, $u$ is for fluid velocity, $k$ is for fluid thermal conductivity ratio, $C$ and $m$ are for the constants determined by test.

The total power of the pump and the fan is[7]

$$
P=P_{\text {pump }}+P_{\text {fan }}=\frac{\Delta p_{\text {pump }} \quad q_{\text {pump }}}{\varepsilon}+\frac{\Delta p_{\text {fan }} q_{\text {fan }}}{\varepsilon}
$$

Where $q_{\text {pump }}$ is for the pump flow rate, $q_{\text {fan }}$ is for the flow of the fan, $\Delta p_{\text {pump }}$ is for pump pressure rise, $\Delta p_{\text {fan }}$ is promoted to the pressure of the fan, $P_{\text {pump }}$ is for pump power, and $P_{\text {fan }}$ is for the power of fan.

\section{Verification of Cooling System Model on Test Bench}

The structure of bench device is shown in Fig. 1, of which the data acquisition system and controller use America national instruments NI cDAC-9188. CRIO-9022. The water pump and fan are driven by electric motor with steeples speed regulation. The fan is used to generate wind to the simulation vehicle speed. The parameters are shown in Table 1. During the test, the ambient atmospheric pressure is $101 \mathrm{kPa}$ on average and the average temperature is $30{ }^{\circ} \mathrm{C}$. In response to the static and dynamic comprehensive verification of the cooling system, select Table 2 , idle speed, climbing three typical working conditions are conducted, and the simulation values are compared to the experimental value.

Table 1: Engine Parameters

\begin{tabular}{|l|l|}
\hline items & Parameter \\
\hline Compression ratio & 9.3 \\
\hline The number of cylinders & four cylinders in line \\
\hline Stroke & Four \\
\hline Bore & 78.7 \\
\hline Trip & $69 \mathrm{~mm}$ \\
\hline Maximum power & $65 \mathrm{~kW}(6000 \mathrm{r} / \mathrm{min})$ \\
\hline Maximum torque & $115 \mathrm{~N} \cdot \mathrm{m}(3200 \mathrm{r} / \mathrm{min})$ \\
\hline
\end{tabular}




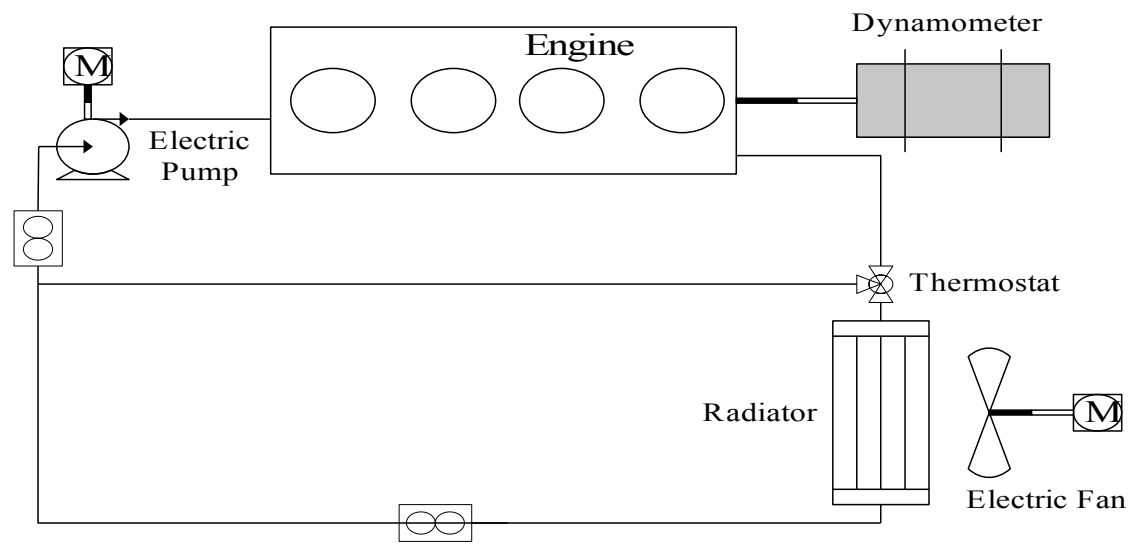

Figure 1 : Diagram of Experimental Apparatus

\begin{tabular}{|l|l|l|l|l|}
\hline $\mathrm{t} / \mathrm{s}$ & $\begin{array}{l}\text { Simulated } \\
\text { working condition }\end{array}$ & Speed $/(\mathrm{r} / \mathrm{min})$ & Load $/ \%$ & $\begin{array}{l}\text { Simulated vehicle } \\
\text { speed } /(\mathrm{km} . \mathrm{h}-1)\end{array}$ \\
\hline $1-600$ & idling speed & 800 & 10 & 0 \\
\hline $601-1200$ & high speed & 2710 & 70 & 90 \\
\hline $1201-1800$ & climbing & 2330 & 85 & 30 \\
\hline
\end{tabular}

Table 2 : Parameter Conditions vs Time

Test and simulation results are both shown in Fig. 2, from which we can get the analysis that the engine coolant outlet temperature calculation and the experimental values have the same trend, and the engine water pump in the experiment with the engine crankshaft speed is fixed the rotation ratio, which thus result in the difference at $600 \mathrm{~s}$ and at $200 \mathrm{~s}$ in the operating condition because the engine dynamometer control needs a period of time.

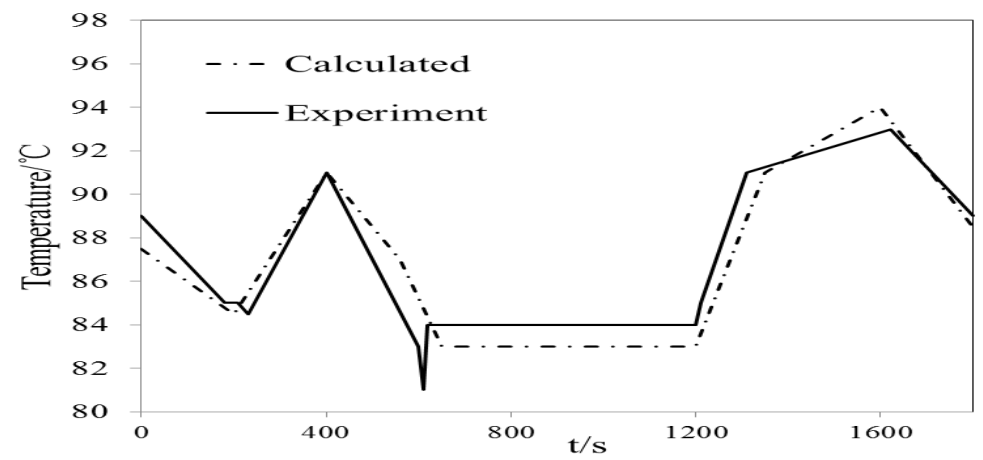

Figure2 : Contrast of Simulated and Tested Engine Coolant Outlet Temperatures

\section{The Cooling System Control Algorithm}

At present, the control strategy used in intelligent engine cooling system is PID control algorithm, which is simple, good reliability, but the engine cooling system has multi input and multi output, nonlinear, hysteresis characteristics, and the car with a large range of working conditions, the PID control algorithm cannot meet the coolant temperature control and reduce the energy consumption of the cooling system. 


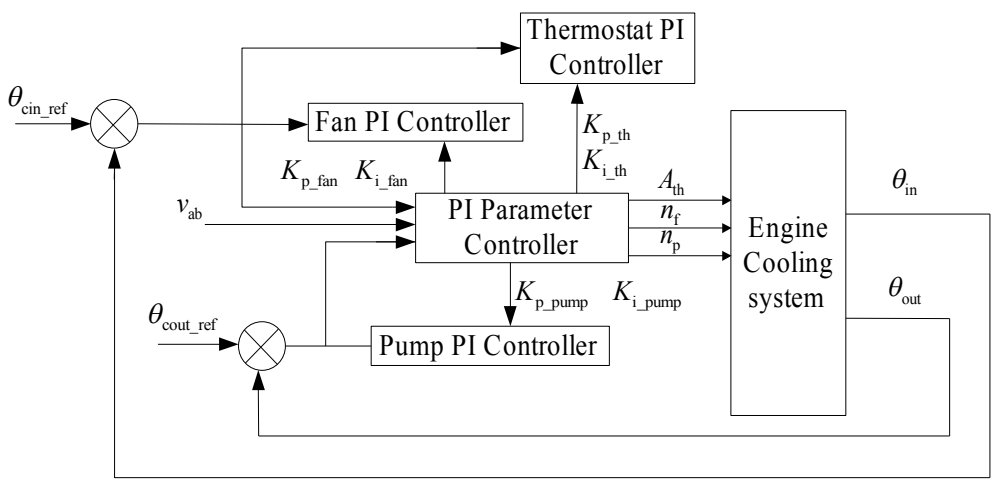

Figure 3: Control Model with PI Feedback

The attachment feed-forward control according to the working conditions of engine cooling capacity of the cooling system is predicted. According to the change of environmental temperature and control of the vehicle speed, it can effectively solve the problem of hysteresis control cooling system; in this sense, feed forward and feedback of the comprehensively control can take into account the stability of the coolant temperature control and speed, shorten the transition time, avoid overshoot, and reduce the energy consumption of the cooling system.

\subsection{PI Feedback Control}

The vehicle engine operating conditions change frequently. There are obvious nonlinear characteristics. So the application of differential items is removed. At the same time, variable gain PI control algorithm is used to control the cooling system pump, a fan and an electric thermostat respectively. At the inlet and outlet of the engine coolant collect the temperature $\theta_{\text {c_in }}, \theta_{\text {c_out }}$. By adjusting the open degree $A_{\text {th }}$ of electric thermostat and the speed of the fan, the engine coolant inlet temperature $\theta_{\text {c_ } \_ \text {in }}$ is closedloop controlled to track the target temperature $\theta_{\text {inout_ref }}$. So define:

$$
\begin{gathered}
\Delta \theta_{\text {c_ref }}=\theta_{\text {cout_ref }}-\theta_{\text {cin_ref }} \\
\Delta \theta_{\text {c }}=\theta_{\text {c_out }}-\theta_{\text {c_ } \_ \text {in }}
\end{gathered}
$$

As to the engine coolant inlet and outlet temperature difference $\Delta \theta_{c}$, ensure the cooling water jacket, prevent local overheating, need to limit, in the defined coolant export target temperature of $\theta_{\text {cout_ref }}=90^{\circ} \mathrm{C}, \Delta \theta_{\text {c_ref }}=6^{\circ} \mathrm{C}$, the engine coolant $\theta_{\text {cin_ref }}=84^{\circ} \mathrm{C}$.

\subsection{Feedback Control Based on PI}

The engine body and the coolant have a large heat capacity. So when the operating condition of the engine changes, the process that the combustion chamber transfer heat to the coolant and the heat through the radiator tank is emitted to the environment lags behind.

The feed forward controller is based on the engine speed $n_{\text {eng }}$ and load $D_{\text {eng }}$, and the heat dissipating capacity of cooling system $Q_{\text {eng }}$ is obtained.

The import and export target temperature required by the coolant flow can be obtained. By Formula (4.1) to obtain the pump feed forward output value, with the PI output, the feedback values are summed. The design is based on the feed forward control method. Due to the effect of feed forward control, the ratio and derivative terms of the pump PI feedback control should be reduced appropriately to keep the control system having considerable stability and speediness. 


\section{Simulation Analysis}

The NEDC conditions are used to compare the control effect of the original machine control, PI control, feed forward feedback control of a PI feedback. NEDC contain $1180 \mathrm{~s}$, including 4 ECE and 1 EUDC. In the NEDC cases the control method of the low speed motor starts and stops frequently in the urban and high speed in suburban may be comprehensively investigated. In the computation model, set the engine cooling system warming when temperature is up to $80^{\circ} \mathrm{C}$, the environmental temperature of ${ }^{\circ} \mathrm{C}$. Results are shown with 3 control modes. The temperature of cooling system fluctuates in the urban cycle, from $85{ }^{\circ} \mathrm{C}$ to $91{ }^{\circ} \mathrm{C}$. The temperature of coolant, according to Table 3 shows in the suburbs of circulating cooling system, fluctuates in the urban cycle, from $85{ }^{\circ} \mathrm{C}$ to $91{ }^{\circ} \mathrm{C}$.

\begin{tabular}{|l|l|l|l|l|}
\hline Condition & Control Strategy & $\mathrm{P}_{\text {pump }} / \mathrm{W}$ & $\mathrm{P}_{\text {fan }} / \mathrm{W}$ & $\mathrm{P} / \mathrm{W}$ \\
\hline \multirow{4}{*}{ ECE } & Initial & 148.4 & 24.6 & 173 \\
\cline { 2 - 5 } & PI & 69.7 & 21.4 & 91.1 \\
\cline { 2 - 5 } & integrated & 68.6 & 13.3 & 81.9 \\
\hline \multirow{3}{*}{ EUDC } & Initial & 304.5 & 9.1 & 313.6 \\
\cline { 2 - 5 } & PI & 109.3 & 3.8 & 113.1 \\
\cline { 2 - 5 } & integrated & 113.1 & 0.5 & 113.7 \\
\hline \multirow{3}{*}{ NEDC } & Initial & 201.3 & 19.3 & 220.7 \\
\cline { 2 - 5 } & PI & 83.1 & 15.4 & 98.6 \\
\cline { 2 - 5 } & integrated & 83.7 & 9 & 92.7 \\
\hline
\end{tabular}

Table 3 : Parasitical Loss of the Cooling System

As shown in Table 3, Power consumption of water pump and fan of each cycle cooling are compared which are calculated through Equation (2.5). Power consumption for each working condition is under the power of the time average. PI feedback control and integrated control in urban, suburban, and the new European driving cycle (NEDC) compared to the original engine control mode have been reduced by more than $50 \%$ of the power consumption of water pump.

\section{Conclusion}

PI feedback control strategy in the car in the NEDC mode makes that the fluctuation of temperature of coolant at import and export of engine is less than $\pm 1.5^{\circ} \mathrm{C}$. To avoid large fluctuations in the cooling system temperature and improve the reliability of cooling system, the application of feed forward integrated control system can adjust the coolant flow rate according to the engine condition timely, and further the temperature fluctuation is reduced by $\pm 0.5^{\circ} \mathrm{C}$.

\section{References}

[1] Pang H H, Brace C J. Review of engine cooling technologies for modern engines[J]. Proceedings of the Institution of Mechanical Engineers, Part D: Journal of Automobile Engineering, 218(11):1209-1215(2004).

[2] Cho, H., Jung, D., Pilipi, Z., Assanis, D., Vanderslice, J., and Bryzik, W., Application of Controllable Electric Coolant Pump for Fuel Economy and Cooling Performance Improvement [J], Journal of Engineering for Gas Turbines and Power, 129(1): 239-244(2007).

[3] IIhan Bayraktar . Computational Simulation Methods for Vehicle Thermal Management[J]. Applied Thermal Engineering, 36(2012):325-329(2012)

[4] Choi K W, Kim K B, Lee K H. Effect of new cooling system in a diesel engine on engine performance and emission characteristics [J]. SAE International Journal of Engines, 2(2009-010177): 77-82(2009)

[5] Salah M H, Mitchell T H, Wagner J R, et al. Nonlinear-control strategy for advanced vehicle thermal-management systems[J]. Vehicular Technology, IEEE Transactions on, 57(1): 127137(2008) 
[6] Setlur P, Wagner J R, Dawson D M, et al. An advanced engine thermal management system: Nonlinear control and test [J]. Mechatronics, IEEE/ASME Transactions on, 10(2): 210-220(2005)

[7] Chen Q, Fu R H, Xu Y C. Electrical circuit analogy for heat transfer analysis and optimization in heat exchanger networks[J]. Applied Energy, 139: 81-92(2015) 